\title{
SEROEVIDENCE OF CHLAMYDIA TRACHOMATIS INFECTION IN INFERTILE MALE AND ITS ASSOCIATION WITH SEMEN QUALITY IN UNIVERSITY OF BENIN TEACHING HOSPITAL, BENIN CITY, NIGERIA
}

\author{
KK .O. Ibadin, ${ }^{* *}$ O. I. Enabulele, ${ }^{* *}$ N. O. Eghafona, ${ }^{* * *}$ A. P. Osemwenkha \\ *Human Reproduction Research Program (HRRP) Department of Obstetrics \& \\ Gynecology, University of Benin Teaching Hospital, Benin City. ${ }^{* *}$ Department of \\ Microbiology, Faculty of Life Sciences, University of Benin, Benin City. \\ ${ }^{* * *}$ Department of Obstetric and Gynecology, University of Benin, Benin City.
}

\section{Correspondence:}

Mr K .O. Ibadin

Human Reproduction Research Program (HRRP)

Dept of Obstetrics \& Gynecology

University of Benin

Benin City, Nigeria

Email: kenbadin@yahoo.com

\section{ABSTRACT}

Given the lack of information concerning the role of Chlamydia trachomatis in male infertility, it has become imperative to analyse the quality of semen of male with seroevidence of antibody to Chlamydia trachomatis infection. A total of 156 male patients attending the Human Reproduction Research Programme/ Invitro Fertililzation Centre of University of Benin Teaching Hospital (UBTH) Benin City, Edo state were enrolled into this study. Standard semen analysis and serological investigation of Chlamydia trachomatis were done for each male patient according to the laboratory diagnosis of sexually transmitted diseases of WHO (1999). Chlamydia trachomatis antibody was found to be Seropositive in $37(24 \%)$ male patients. Standard semen analysis showed abnormality in the various semen parameters of the seropositive male patients. The Seminal fluid analysis of the Seropositive male patients had total average mean sperm morphology of $11.0 \%$ (normal), total sperm count $\left(10.0 \times 10^{6}\right) \mathrm{ml}$, motility $(11.0 \%)$ vitality $(17.0 \%)$ (live) and leucocyte count $1.5 \times 10^{6} \mathrm{ml}$ lower than the average mean sperm morphology of $28.0 \%$, vitality $63 \%$, total sperm count $\left(30.5 \times 10^{6} \mathrm{ml}\right)$, motility $(61.0 \%)$ and leucocyte count $\left(0.5 \times 10^{6} \mathrm{ml}\right)$ of the 28 age-matched male subject used as control $(P<0.05)$. This study indicates that Chlamydia trachomatis may be an independent risk factor affecting semen quality of male and consequently infertility.

Key words: Serology, Chlamydia trachomatis, sperm quality.

\section{INTRODUCTION}

Chlamydia trachomatis infection is the most prevalent sexually transmitted bacterial infection throughout the world ${ }^{1}$. While some authors are convinced that Chlamydia infections in male can lead to serious problems while others are less certain and have argued that its effects on female reproduction are far more important with far reaching consequences ${ }^{2}$.

In an attempt to link Chlamydia infection in male with reproductive problems, a number of studies have investigated the relationship between the infection and semen quality. However, some studies have shown that infection is associated with poorer 
semen quality while others have claimed that it is not ${ }^{3}$. Another school of thought believed that Chlamydia trachomatis infection may influence infertility by inducing sperm autoantibodies or by impairing more subtle aspects of sperm quality not registered by conventional techniques ${ }^{4,5}$. Furthermore, increased incidence of Chlamydia trachomatis has been found in male with obstructive azoospermia ${ }^{4}$. Unlike IgG, $\lg A$ is an immunoglobulin which is secreted locally in response to relatively more recent infection. A study has reported elevated levels of IgA in the seminal plasma of $27 \%$ of male patient with reproductive problem or sub fertility ${ }^{3}$.

More recently, authors have measured Chlamydia specific immunoglobulin either in serum or seminal plasma, One of them measure Chlamydia specific serum lgG in 50\% sub fertile male group with a previous genital infection ${ }^{6}$. This has led to confusion in the literature, but in reality, the studies are frequently not comparable because of different, and inadequate, diagnostic methods and test specimens used to identify those male with Chlamydia infection. For example, a number of studies have based their diagnosis on an attempt to culture Chlamydia trachomatis from ejaculates or urethral swabs however; seminal plasma is known to be inhibitory to the effective culture of Chlamydia trachomatis ${ }^{6}$. Other studies have attempted to overcome these problems by attempting to use serological method although the detection of serum antibodies of Chlamydia trachomatis in asymptomatic male is not particularly helpful ${ }^{5}$. Moreover, because the immune response differs between individuals, it is not always clear whether a single elevated antibody titer represents an active or current infection to which a strong immune response was generated. In this situation, all that can be said is that the detection of antibody to Chlamydia trachomatis in the serum or seminal plasma of men is suggestive current or active Chlamydia trachomatis infection.

This study attempts to determine the Seroprevalence of Chlamydia trachomatis infection and its association with semen quality of male undergoing Assisted Reproduction Technology (ART)

\section{MATERIALS AND METHODS}

A total of 156 male patients were recruited or enrolled in this study with 28 age-matched male with normozoospemia used as control. All the male patients were undergoing semen analysis as part of the mandatory work-up for infertility investigation for possible Assisted Reproduction Technology/ Invitro Fertilization Programme after failing to conceive with their partner after at least 1 to 2 years of marriage and unprotected sexual exposure. None of the male patient reported any symptoms of genitourinary infections and was therefore considered asymptomatic of Sexually Transmitted Diseases. There was no age restriction and structured questionnaire were distributed to ascertain their social demographic history.

Seminal fluid analysis: Prior to semen analysis, the male patients were provided with written information and were asked to abstain from sexual intercourse for 3-5days before the seminal fluid analysis. All samples for analysis were produced on site through masturbation or coitus interruptus and collected into standard containers that had previously been shown not to have any cytotoxic effects on human spermatozoa according to the methods outlined in 
World Health Organizations (WHO 1999). The semen was allowed to stay for up to 30 minutes to liquefy at $37^{\circ} \mathrm{C}$ before the analysis. Semen analysis was performed according to $\mathrm{WHO}$ (1999) guidelines with all the measures of semen quality parameters i.e. Sperm morphology, sperm motility, sperm vitality, concentration and leucocyte enumeration. EosinNegrosin and Papanicolaou stains were used to performed sperm morphology and vitality tests respectively according to WHO (1999) criteria.

The laboratory employed a comprehensive internal quality control programme for semen analysis based on World Health Organization's $10^{\text {th }}$ Semenology and Cervical Cytology workshop 2008.

Seroanalysis of Chlamydia trachomatis: $4 \mathrm{mls}$ of Blood sample was collected from each male patient by trained phlebotomist the blood was allowed to clot to aspirate the serum for the serodetection of the antibody to Chlamydia trachomatis using the Immunocomb Chlamydia trachomatis IgG test which is an indirect solid phases Enzyme Immuno Absorbent (EIA) in line with WHO 1999 guidelines (Table II) for the laboratory diagnosis of Chlamydia trachomatis infection with a performance characteristic of $95 \%$ sensitivity and $90 \%$ specificity. The serodiagnostic kit used was produced by organic Product France

\section{RESULT}

The $37(24 \%)$ of the 156 male patients investigated in this study were found to be seropositive for the antibody to Chlamydia trachomatis with only $1(3 \%)$ of the 31 age-matched controls showed seropositivity (Table I). The data obtained in this study were analysed using the statistical package for social sciences SPSS version 10.0 statistical software. Increase mean leucocytes counts were obtained in semen from seropositive male patients in this study. The corresponding standard semen analysis carried out on the male patients recruited in this study showed abnormal counts in Sperm motility, concentration, morphology, vitality in the investigated seropositive male patients and the mean values of the semen parameters were lower than the mean values of semen parameters obtain in the control subjects $(P<0.05)$.

Table I: AGE CLASSIFICATION OF INFERTILE MALE PATIENTS AND CONTROLS WITH SEROPOSITIVE CHLAMYDIA INFECTION

\begin{tabular}{|c|c|c|c|c|}
\hline & \multicolumn{2}{|c|}{ INFERTILE SUBJECTS } & \multicolumn{2}{|c|}{ CONTROLS } \\
\hline Age (yrs) & No. Examined & $\begin{array}{c}\text { No positive } \\
(\%)\end{array}$ & No. Examined & No. positive (\%) \\
\hline $20-24$ & 9 & $1(11)$ & 1 & $0(0)$ \\
\hline 25-29 & 14 & $3(21)$ & 5 & $0(0)$ \\
\hline $30-34$ & 36 & $6(17)$ & 10 & 1 (10) \\
\hline $35-39$ & 42 & 8 (19) & 9 & $0(0)$ \\
\hline $40-44$ & 28 & $15(53)$ & 4 & $0(0)$ \\
\hline$>45$ & 17 & $4(23)$ & 2 & $0(0)$ \\
\hline & 156 & 37 (24) & 31 & $1(3)$ \\
\hline
\end{tabular}


Table II: MEAN SEMEN QUALITY OF SEROPOSITIVE INFERTILE MALE PATIENTS AND CONTROLS

\begin{tabular}{|c|c|c|c|c|c|c|c|c|c|c|}
\hline & \multicolumn{5}{|c|}{ SEROPOSITIVE } & \multicolumn{5}{|c|}{ CONTROLS } \\
\hline $\begin{array}{l}\text { Age } \\
\text { (Yrs) }\end{array}$ & $\mathrm{Tm}$ & Mor. & Vit. & Tc. & Leu. & $\mathrm{Tm}$ & Mor. & Vit. & Tc. & Leu. \\
\hline $20-24$ & 10 & 8 & 20 & 8.6 & 1.2 & 60 & 30 & 65 & 32 & $\begin{array}{c}0.5 x \\
10^{6}\end{array}$ \\
\hline $25-29$ & 10 & 10 & 15 & 11.2 & 2.4 & 50 & 29 & 69 & 28 & 0.4 \\
\hline $30-34$ & 14 & 8 & 21 & 8.4 & 1.8 & 50 & 25 & 70 & 35 & 0.6 \\
\hline $35-39$ & 9 & 12 & 15 & 10.0 & 1.5 & 48 & 30 & 66 & 28 & 0.3 \\
\hline $40-44$ & 15 & 16 & 20 & 9.6 & 1.7 & 51 & 29 & 72 & 31 & 0.9 \\
\hline$>45$ & 10 & 10 & 12 & 12.4 & 1.4 & 50 & 30 & 67 & 28 & 0.4 \\
\hline $\begin{array}{c}\text { Total } \\
\text { Average }\end{array}$ & 11 & 11 & 17 & 10 & 1.5 & 61 & 28 & 63 & 30 & 0.5 \\
\hline $\begin{array}{l}\text { Keys: } \\
\text { Tm-Total } \\
\text { Mor-Morp } \\
\text { Vit-Vitality } \\
\text { Tc- Total } \\
\text { Leu-Leucc }\end{array}$ & $\begin{array}{l}\text { otility } \\
\text { ology } \\
\text { n \% } \\
\text { serm } \\
\text { sytes }\end{array}$ & $\begin{array}{l}n \\
\% \\
\%\end{array}$ & /ml & $\begin{array}{l}\text { W.H. } \\
>50 \% \\
>30 \% \\
>75 \% \\
>20 \mathrm{n} \\
<1.0 \mathrm{n}\end{array}$ & $\begin{array}{l}\text { Live) } \\
\text { lion/ml } \\
\text { lion } / \mathrm{ml}\end{array}$ & IA 1 & & & & \\
\hline
\end{tabular}

\section{DISCUSSION}

In this study, $37(24 \%)$ of 156 male patients that attended Human Reproduction Research Programme/ Invitro fertilization centre of the hospital were found to be seropositive for Chlamydia trachomatis antibody. The seroprevalence rate of $24 \%$ obtained in this study is similar to the $27 \%$ recorded among subfertile male group in previous studies ${ }^{7}$. Recently, some authors detected Chlamydia specific immunoglobulin in serum or seminal plasma of infertile male patients. One of them detected Chlamydia specific serum IgG in $50 \%$ subfertile male group with a previous genital infection ${ }^{4,7}$. Unlike $\lg G, \lg A$ is an immunoglobulin which is secreted locally in response to relatively more recent infection ${ }^{3,8,9}$.

The seminal fluid analysis obtained among the seropositive infertile male subjects in this study showed abnormalities and decrease count in almost all the semen parameters which further explained the pathological significance of Chlamydia trachomatis in the upper genital tract of male leading to the presence of both white blood cells, dead sperm and antichlamydia antibodies in semen ${ }^{10}$ Furthermore, increased incidence of Chlamydia trachomatis has been found in male with obstructive azoospermia $^{1,9}$. Chlamydia trachomatis infection induces leucoctytocspermia leading to elevated leucocytes-derive reactive oxygen species which damages sperm by causing peroxidation, decrease sperm numbers and impaired sperm motility ${ }^{6,10}$.

In this situation, all that can be said is that the detection of antibody to Chlamydia trachomatis in the serum or seminal plasma of men is suggestive current or active Chlamydia trachomatis infection. Furthermore, increased incidence of Chlamydia trachomatis has been found in male with obstructive azoospermia ${ }^{4}$.

\section{CONCLUSION}

This study supported the initial hypothesis which state that the ejaculate of male whose serum were seropositive for the Chlamydia 
trachomatis antibody would be more likely to contain dead sperms and therefore would more likely be asthenozoospermic or necrozoospermic.

It is hereby recommended based on the findings from this study that seminal plasma or serum of infertile male patients and their female partners attending fertility clinic should be screened for Chlamydia trachomatis infection.

\section{REFERENCES}

1. Gdoura R, Kchaou W, AmmarKeskes L, Chakroun N, Sellemi A, Znazen A, Rebai T, Hammami A. Assessment of Chlamydia trachomatis, Ureaplasma urealyticum, Ureaplasma parvum, Mycoplasma homins, and Mycoplasma Asymptomatic Male Partner of Infertile Couples. J Androl. 2008; 29(2):198-206.

2. Hamdad-Dooudi F, Petit J, Eb F. Assessment of Chlamydia trachomatis infection in asymptomatic male partners in infertile couples J. Med. Microbiol. 2004; 53(10):985990.

3. Eggert-Kruse W, Rohr G, Demirakca T. et al. Chlamydial serology in 1303 asymptomatic subfertile couples. Hum. Reprod. 1997; 12:1464-1475.

4. Idahl A, Boman J, Kumlin U, Olofsson JL. Demonstration of Chlamydia trachomatis IgG antibodies in the male partner of the infertile couple is correlated with a reduced likelihood of achieving pregnancy Hum. Reprod. 2004; 19(15):11211126.

5. Treharne JD. Chlamydia serology. British Medical Bulletin. 1993; 39:194-200.

6. Hosseinzadeh S, Eley A, Pacey AA. Semen quality of Men with asymptomatic chlamydial infection. J Androl. 2004; 25(1): 104-109.

7. Auroux MR, De Mouy DM, Acar J. Male fertility and positive chlamydial serology: A study of 61 fertile and 82 subfertile men. J Androl. 1987; 8:197-200.

8. Geris J, Schoysman R, Piessens-F. A possible role of Chlamydia trachomatis as a causative agent in epididymal infertility. Acta Europea Fertlitatis, 1985; 16:179-184.

9. Keck C, Gerber-Schafer C, Clad A, Wihelem C, Breckwoldf M. Seminal tract infections: impact on male and treatment options Hum. Reprod. Update. 1998; 4(6):891-903.

10. Nikanen $V$, Terho $P$, LPunnonen R, Meuraman $\mathrm{O}$. The significance of chlamydial genital infection in male infertility. Arch. Androl. 1990; 4:57-61. 